\title{
The Correlation between Sexuality and Family Functioning among Patients with Inflammatory Bowel Disease in Japan
}

\author{
Yoshiko Miki ${ }^{*}$, Naohiro Hohashi² \\ ${ }^{1}$ Department of Nursing, Faculty of Health Sciences, Kagawa Prefectural University of Health Sciences, Takamatsu, Japan \\ ${ }^{2}$ Division of Family Health Care Nursing, Graduate School of Health Sciences, Kobe University, Kobe, Japan \\ Email: ^miki-y@dhs.pref.ka gawa.jp, naohiro@hohashi.org
}

How to cite this paper: Miki, Y. and Hohashi, N. (2018) The Correlation between Sexuality and Family Functioning among Patients with Inflammatory Bowel Disease in Japan. Open Journal of Nursing, 8, 717730 .

https://doi.org/10.4236/ojn.2018.810054

Received: September 18, 2018

Accepted: October 27, 2018

Published: October 30, 2018

Copyright $\odot 2018$ by authors and Scientific Research Publishing Inc. This work is licensed under the Creative Commons Attribution International License (CC BY 4.0).

http://creativecommons.org/licenses/by/4.0/

\begin{abstract}
Purpose: The objective of this study was to examine the correlation between the sexuality of patients with Inflammatory Bowel Disease and family functioning. Methods: The study took the form of a self-administered questionnaire survey, utilizing the Sexuality Satisfaction Index for IBD (SEXSI-IBD) for measuring sexuality and the Survey of Family Environment Survey of Family Environment (SFE) for measuring family functioning. SEXSI-IBD consists of 28 items and five domains, and SFE consists of 30 items and five domains. The participants were recruited at 15 self-help groups and 14 hospitals. Results: Of 146 participants, $48.6 \%$ were male and $52.4 \%$ female, with an average age of 41.1 years. A significant correlation was observed between the item average score of SEXSI-IBD and Overall Satisfaction Score (OSS) of SFE. Significant correlations were observed in two domains of the SEXSI-IBD, "Daily interaction" and "Sexual communication," and in all five domains of the SFE. In particular, for "Daily interaction," the strongest correlation was observed in the SFE's "Macro system" and "Family internal environment system." A correlation was observed between the "Physical contact importance" in SEXSI-IBD and the "Macro system" in the OSS of the SFE. Conclusions: Sexuality correlates with family functioning not only in the family internal environment system but also in the family external environment system. Through an approach aimed at elevating the degree of satisfaction for sexuality, it becomes possible to improve family functioning and realize a sense of family well-being.
\end{abstract}

\section{Keywords}

Sexuality, Sexuality Satisfaction Index, SEXSI-IBD, Family Functioning, Inflammatory Bowel Disease 


\section{Introduction}

Inflammatory bowel disease (IBD) refers to a group of idiopathic chronic inflammatory intestinal conditions. IBD includes ulcerative colitis (UC) and Crohn's disease (CD). Both UC and CD usually involve severe diarrhea, abdominal pain, fatigue, and weight loss. These forms of IBD can be debilitating and sometimes lead to life-threatening complications. Most people who develop IBD are diagnosed between the ages of 15 and 40 years [1].

The recurrence of IBD symptoms and necessity for treatment are factors in lowered self-image and self-esteem, as well as anxiety, depression, and sexual dysfunction. These symptoms are believed to occur with mutual influence [2] [3]. For many patients, IBD has an impact on marriage and childbirth and impedes the forming of a family as well as empowerment of the family, with effects extending to family functioning [4] [5]. Consequently, IBD patients face problems involving sexuality and family functioning, which involve both relations between spouses and family functioning. By clarifying the ways in which these issues relate may provide suggestions as to where approaches should be taken.

We, in a previous study, conducted a concept analysis of sexuality. From the results, as the defining attributes of sexuality, "mutual interaction between an individual's sexual characteristics and sexual partner" was extracted, with the consequences found to be "family well-being". Consequently, sexuality is considered an objective for realizing family well-being, or in other words, enhancing family functioning [6]. The husband and wife are a subsystem that forms the basis of the family system unit, and a married couple that engages in sexual relations relates to family functioning as a whole.

Moreover, relationships between sexual contentment, family functioning and marital functioning were quantitatively established [7]. However, it is generally believed that both sexuality and family functioning encompass complex factors, and in the real world no research exists that explains concretely how they relate to one another.

This study of IBD patients aimed to describe the relationship between sexuality and family functioning through utilization of questionnaire items that include concrete expressions of the respective phenomena. It is believed that the descriptions of the relationship between sexuality and family functioning will provide data for considering methods of intervention for IBD patients and their families.

\section{Methods}

\subsection{Participants}

Because the measurements utilized contained questions related to the participants' sexual behavior, the participants were limited to those with a sexual partner and conditional on having been diagnosed with IBD. The age of the participants was limited to between the ages of 20 to 79 years. Japan is a super-aged society with a high ratio of elderly persons, and as both middle-aged and elderly 
people engage in sexual behavior, the elderly were also included. Also considering ability to respond to the questions, the upper age limit was set at 79 years.

The form of the study was a self-administered questionnaire survey concerning basic characteristics, sexuality and family function scales among IBD patients. We recruited participants at 15 self-help groups and 14 hospitals. The offices of the self-help groups sent survey forms to the patients who were members of the group. Hospital staff distributed survey forms to the outpatients who had consented to participate in the study, with the support of the attending physicians. The number of IBD patients in Japan is estimated at about 200,000 people. The sample determination method was made using the estimated population figure, which to put the confidence coefficient at $95 \%$ comes to 384 people. Recruitment of IBD patients for the survey was difficult, but to obtain the largest possible number of samples, the target was set at 384 participants. The survey was conducted between June 2013 and February 2015.

\subsection{Questionnaires}

\subsubsection{Operational Definition of Basic Terms}

The operational definition of sexuality was defined as "individual sexual characteristics and interaction with sexual partners." We developed this operational definition using conceptual analysis methods from a previous study [6]. Family functioning is defined as "family's cognitive activities performed by a family system unit and its cognitive abilities to act on the family environment through the performance of individual family members' roles."

\subsubsection{Basic Characteristics}

As for basic characteristics of participants, we inquired regarding sex, age, disease (specifying either UC or CD), and presence of stoma.

\subsubsection{Sexuality Satisfaction Index for IBD (SEXSI-IBD)}

As for sexuality, the SEXSI-IBD was utilized [8]. This is a self-administered questionnaire for measuring the sexuality of IBD patients, and its reliability and validity have been established. The SEXSI-IBD has five domains for measuring both the sexual characteristics of individuals and the interaction with their sexual partners. Consequently we believe it is possible to achieve the objectives of this study, which were to link family functioning and sexuality. The SEXSI-IBD is showed in Appendix. SEXSI-IBD consists of 28 items and five domains with a 5 -point Likert scale $(0=$ strongly disagree, $4=$ strongly agree $)$. A higher score indicates a greater level of satisfaction. The mean scores of the SEXSI-IBD scales were calculated as the item average scores, so the scores are not affected by missing values. The five domains of the SEXSI-IBD are as follows: daily interaction; sexual communication; sexual difficulty; sexual interest; and importance of skin ship. The skin ship is a Japanese English word which means physical contact.

\subsubsection{Survey of Family Environment (SFE)}

The SFE, based on the Hohashi's Concentric Sphere Family Environment Theory 
(CSFET) [9], examines families' functioning, i.e., satisfaction score (SS), and needs for family support, i.e., needs score (NS). For the indicators of this study, the SS of the SFE was utilized. The SFE enables measurement of family functioning from five comprehensive domains, and its reliability and validity have been confirmed [10]. Consequently, the SFE is believed to usable for comprehensively measuring the ways in which sexuality relates to family functioning. The SFE consists of 30 items structured into the following domains: supra system, macro system, micro system, family internal environment system, and chrono system. Participants assign a satisfaction score (SS) using a 5 -point Likert scale ( $1=$ dissatisfied, $5=$ satisfied). The mean scores of the SFE scales were calculated as the item average scores, so the scores are not affected by missing values.

\subsection{Statistical Analyses}

All statistical analysis used SPSS 21.0 for Microsoft Windows (IBM Corp.) and Spearman's correlation coefficient (rs) to measure the statistical relationship between two continuous variables. A $p$ of less than 0.05 was considered statistically significant. First correlation was considered between the five domains of SEXSI-IBD and the five domains of the SFE. Next, correlation was extracted between the 28 items of SEXSI-IBD and the 30 items of SEF, and then correlation was considered between the items in domains regarded as having correlative relationships.

\subsection{Ethical Considerations}

The present study was conducted following the obtaining of approval of the Institutional Review Board of Shikoku University and Kagawa Prefectural University of Health Sciences in Japan.

Written explanations were provided to the participants, stating that participation in the survey must be based on their own free will, they had the right to refuse to participate, they would not be subjected to negative treatment if they refused participation, and their personal data would be treated as strictly confidential.

In the self-administered questionnaire survey, returning the questionnaire was regarded as the consent for participation in the study. For patients who were members of the self-help groups, the survey forms were sent via the offices of the self-help groups by mail. The outpatients received survey forms from the hospital staff in charge. To give due consideration to confidentiality, we asked the participants to send back the survey forms directly to the researchers. These data are to be stored in a locked safe for five years after the completion of the study, and are to be discarded thereafter.

\section{Results}

\subsection{Demographic Data}

A total of 757 questionnaire forms were distributed, with 166 forms returned (a 
response ratio of $21.6 \%$ ). Fourteen forms were invalidated due to no responses to questions pertaining to any of the five domains of SEXSI-IBD, and likewise when more than four items of the SFE received no replies. That gave a total of 146 valid responses (a response ratio of 19.0\%).

Table 1 shows the demographic data of the 146 participants. Average age was 41.1 years, with $48.6 \%$ of the participants male and $51.4 \%$ female. The percentage having stoma was $36.3 \%$. Participants with UC only were $57.5 \%$, CD only $41.1 \%$, and with both UC and CD, $0.7 \%$.

\subsection{Correlation between Five Domains of SEXSI-IBD and Five Domains of SFE}

Table 2 indicates the correlation between the five domains of SEXSI-IBD and five domains of SFE. The rs of the mean SEXSI-IBD scores and mean SFE score was 0.334 , indicating significant correlation. Significant correlation between two domains of SEXSI-IBD, "Daily interaction" and "Sexual communication," and four domains of SFE except for "Supra system," was observed. The rs of "Physical contact importance" of SEXSI-IBD was 0.203 in mean score of SFE and 0.255 in "Macro system" of SFE, both showing significant correlation. The "Daily interaction" of SEXSI-IBD and "Family internal environment system" and "Macro system" of SFE indicated an rs of above 0.3 .

Table 1. Participants' Characteristics $(n=146)$.

\begin{tabular}{cc}
\hline Sex & $71(48.6)$ \\
Male & $75(51.4)$ \\
Age & $41.1(11.1)$ \\
\hline Age groups & $3(2.1)$ \\
\hline $20-29$ & $48(32.9)$ \\
$30-39$ & $47(32.2)$ \\
$40-49$ & $30(20.5)$ \\
$50-59$ & $14(9.6)$ \\
$60-69$ & $4(2.7)$ \\
$70-79$ & \\
\hline Disease & $84(57.5)$ \\
UC & $60(41.1)$ \\
CD & $1(0.7)$ \\
UC and CD & $1(0.7)$ \\
No answer & \\
\hline Presence of stoma & $53(36.3)$ \\
Yes & $91(62.3)$ \\
No & $2(1.4)$ \\
No answer & \\
\hline
\end{tabular}

Data are presented as $n(\%)$; age refers to mean years and $S D$. Percentages may not add up to $100 \%$ because of rounding. UC: Ulcerative colitis, CD: Crohn's disease. 
Table 2. Correlation between domains of SEXSI-IBD and SFE $(n=146)$.

\begin{tabular}{ccccccc}
\hline & Sup & Mac & Mic & Int & Chr & $\begin{array}{c}\text { Mean score } \\
\text { of SFE }\end{array}$ \\
\hline Daily interaction & 0.143 & $0.384^{* *}$ & $0.258^{* *}$ & $0.427^{* *}$ & $0.206^{*}$ & $0.420^{* *}$ \\
Sexual communication & $0.174^{*}$ & $0.316^{* *}$ & $0.258^{* *}$ & $0.302^{* *}$ & $0.245^{* *}$ & $0.350^{* *}$ \\
Sexual difficulty & -0.092 & 0.123 & 0.069 & 0.025 & 0.080 & 0.067 \\
Sexual concern & 0.005 & 0.153 & 0.044 & 0.094 & 0.091 & 0.111 \\
Physical Contact Importance & 0.099 & $0.255^{* *}$ & 0.145 & $0.165^{*}$ & 0.095 & $0.203^{\star}$ \\
Mean score of SEXSI-IBD & 0.095 & $0.339^{* *}$ & $0.217^{* *}$ & $0.306^{* *}$ & $0.215^{* *}$ & $0.334^{* *}$ \\
\hline
\end{tabular}

Spearman correlation coefficients ( $\mathrm{rs}$ ) are shown. ${ }^{*} p<0.05,{ }^{* *} p<0.01$. Sup: Supra system, Mac: Macro system, Mic: Micro system, Int: Family internal environment system, Chr: Chrono system.

\subsection{Correlation between Items in SEXSI-IBD and SFE}

Between the mean scores of SEXSI-IBD and four domains of SFE, correlation was observed in "Macro system" and "Micro system," which include transactions among the family external environment system and the family, in "Family internal environment system," which include interactions among family members, and also in "Chrono system," which include transformations of the family external environment system and family internal environment system through the passage of time. With regard to how sexuality relates to the interaction between family members, and in what way transactions occur in the family environment system, and reviewing and noting the items involved in the correlation between SEXSI-IBD and SFE, concrete explanations of the phenomena can be made. Below, we have focused on correlation between two domains of SEXSIIBD ("Daily interaction" and "Sexual communication") and two domains of SFE ("Family internal environment system" and "Micro system") and consider their relevance.

\subsubsection{Correlation between "Daily Interaction" and "Sexual Communication" of SEXSI-IBD and "Family Internal Environment System" of SFE}

Table 3 indicates the correlation between 16 items in SEXSI-IBD (ten items of "Daily Interaction" and six items of "Sexual communication") and 11 items in the "Family internal environment system" of SFE.

A correlation was observed between the "Daily interaction" item "I think that my partner shows consideration to me" and nine of 11 items of SFE. In particular, the rs indicated correlation of above 0.4 between the four SFE items of "Bonds of affection between family members," "Family members' being comfortable at home," "Family's cherishing family time spent together at home," and "Family members' cooperation in child rearing." Among these, "Family members' being comfortable at home" showed the highest correlation, with an rs of 0.550 .

The "Daily interaction" item, "My partner tries to understand my wishes and needs during everyday life," showed an rs of above 0.4 with the SFE item, "Family members' cooperation in child rearing." 
Table 3. Correlation between "Daily interaction" and "Sexual communication" of SEXSI-IBD and "Family internal environment system" of SFE $(n=146)$.

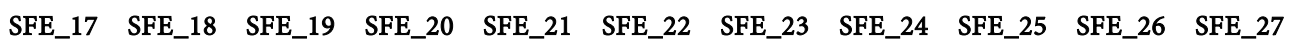

\section{Daily interaction}

1) I think that my partner

shows consideration to me

\author{
$0.433^{* *} \quad 0.550^{* *} 0.282^{* *}$
}

2) My partner tries to understand my wishes and needs during everyday life

3) I am satisfied with the times I spend with my partner

4) I verbally express thoughts and ideas to my partner during everyday life

5) My partner verbally expresses thoughts and ideas to me during everyday life

6) I show consideration to my partner

7) I verbally express love to my partner

8) My partner verbally expresses love to me

9) I understand my partner's wishes and needs during everyday life

\section{Sexual communication}

11) My partner verbally expresses sexual satisfaction to me

\begin{tabular}{|c|c|c|c|c|c|c|c|c|c|c|}
\hline $0.194^{*}$ & $0.358^{\star *}$ & $0.179^{*}$ & 0.116 & $0.185^{\star}$ & $0.202^{*}$ & $0.451^{\star *}$ & $0.238^{\star *}$ & 0.085 & 0.126 & $0.259^{\star *}$ \\
\hline $0.166^{*}$ & $0.376^{\star *}$ & $0.180^{*}$ & 0.079 & $0.206^{\star}$ & $0.176^{\star}$ & $0.401^{* *}$ & $0.222^{\star *}$ & 0.020 & 0.107 & $0.204^{\star}$ \\
\hline 0.107 & 0.162 & 0.136 & 0.033 & 0.131 & 0.058 & $0.290^{*}$ & 0.139 & 0.001 & 0.051 & 0.096 \\
\hline $0.187^{\star}$ & $0.265^{\star *}$ & $0.174^{*}$ & 0.030 & $0.183^{\star}$ & 0.136 & $0.410^{\star *}$ & $0.198^{*}$ & 0.036 & 0.106 & 0.155 \\
\hline $0.254^{\star *}$ & $0.261^{\star *}$ & $0.202^{\star}$ & $0.235^{\star \star}$ & $0.203^{\star}$ & $0.182^{\star}$ & $0.238^{\star}$ & 0.120 & 0.247 & $0.187^{\star}$ & $0.229^{\star *}$ \\
\hline 0.144 & $0.262^{\star *}$ & 0.099 & 0.132 & $0.244^{\star *}$ & 0.105 & $0.292^{\star}$ & 0.162 & 0.131 & 0.161 & 0.143 \\
\hline
\end{tabular}

12) My partner verbally expresses sexual desire to me

13) I verbally express sexual satisfaction to my partner

14) I am satisfied with the content of our sexual relations

15) I verbally express sexual desire to my partner

16) I am satisfied with the frequency of our sexual relations

Spearman correlation coefficients (rs) are shown. ${ }^{*} p<0.05,{ }^{* *} p<0.01$. SFE_17: Bonds of affection between family members, SFE_18: Family members' being comfortable at home, SFE_19: Meeting with family members to discuss, and resolve, concerns and problems, SFE_20: Managing the family budget, SFE_21: Family's cherishing family time spent together at home, SFE_22: Family members' observing family rules, SFE_23: Family members' cooperation in child rearing, SFE_24: Family members' cooperation in doing household chores, SFE_25: Family members' cooperation in providing care during illness and convalescence, SFE_26: Managing family members' diet, SFE_27: Managing family members' physical and mental health. 
Correlation was observed between the "Daily interaction" item "I am satisfied with physical contact, such as hugging or holding hands, during everyday life" and ten of 11 items in SFE. Among these, four items had an rs above 0.4 and two of them ("Family members' being comfortable at home" and "Family members' cooperation in child rearing" had an rs of above 0.5.

In the "Sexual communication" items of SEXSI-IBD, three items ("My partner verbally expresses sexual satisfaction to me," "My partner verbally expresses sexual desire to me," and "I am satisfied with the content of our sexual relations") showed an rs of above 0.4 correlated with the "Family members' cooperation in child rearing" of SFE, with correlation observed between this and all items included in "Sexual communication" of SEXSI-IBD.

\subsubsection{Correlation between "Daily Interaction" and "Sexual Communication" of SEXSI-IBD and SFE "Micro System"}

Table 4 shows the correlation between 16 items of SEXSI-IBD (ten items included in "Daily interaction" and six included in "Sexual communication") and seven items included in the "Micro system" of SFE.

In the "Daily interaction" of the SEXSI-IBD, the highest correlation was observed with three items in the "Micro system": ("I think that my partner shows consideration to me," "I understand my partner's wishes and needs during everyday life," and "I am satisfied with physical contact, such as hugging or holding hands, during everyday life") of SFE. In particular, the rs indicated correlation of above 0.3 between two items ("I understand my partner's wishes and needs during everyday life" and "I am satisfied with physical contact, such as hugging or holding hands, during everyday life") and one item of "Family's interactions with non-cohabitating relatives" of SFE. In addition to two items of SEXSI-IBD, "My partner verbally expresses love to me" and "I am satisfied with physical contact, such as hugging or holding hands, during everyday life," were observed to correlate with one item of SFE ("Family members' receiving emotional support from friends.")

In the "Sexual communication" items in the SEXSI-IBD, a correlation was observed between four items ("I verbally express sexual satisfaction to my partner," "I am satisfied with the content of our sexual relations," "I verbally express sexual desire to my partner," and "I am satisfied with the frequency of our sexual relations") and "Family members' interactions with their friends" in the SFE. Moreover correlation was observed between two items ("I verbally express sexual desire to my partner" and "I am satisfied with the content of our sexual relations") in SEXSI-IBD and "Family members' receiving emotional support from friends" in the SFE.

\section{Discussion}

\subsection{Awareness of Empathy by One's Partner and Emotional Functioning}

No correlation was observed between the item "I think that my partner shows consideration to me" in "Daily interaction" with "Managing the family budget" 
Table 4. Correlation between "Daily interaction" and "Sexual communication" of SEXSI-IBD and "Micro system" of SFE ( $n=$ 146).

\begin{tabular}{|c|c|c|c|c|c|c|c|}
\hline & SFE_10 & SFE_11 & SFE_12 & SFE_13 & SFE_14 & SFE_15 & SFE_16 \\
\hline \multicolumn{8}{|l|}{ Daily interaction } \\
\hline $\begin{array}{l}\text { 1) I think that my partner shows consideration } \\
\text { to me }\end{array}$ & $0.289^{* *}$ & 0.140 & $0.196^{*}$ & $0.192^{*}$ & $0.225^{\star *}$ & 0.068 & $0.213^{*}$ \\
\hline $\begin{array}{l}\text { 2) My partner tries to understand my wishes } \\
\text { and needs during everyday life }\end{array}$ & $0.176^{*}$ & 0.155 & 0.064 & 0.155 & 0.080 & -0.071 & 0.079 \\
\hline $\begin{array}{l}\text { 3) I am satisfied with the times I spend with } \\
\text { my partner }\end{array}$ & 0.142 & 0.128 & 0.083 & 0.152 & 0.043 & -0.004 & 0.066 \\
\hline $\begin{array}{l}\text { 4) I verbally express thoughts and ideas to my } \\
\text { partner during everyday life }\end{array}$ & $0.167^{\star}$ & 0.150 & 0.084 & $0.188^{*}$ & 0.089 & -0.031 & 0.046 \\
\hline $\begin{array}{l}\text { 5) My partner verbally expresses thoughts and } \\
\text { ideas to me during everyday life }\end{array}$ & $0.179^{*}$ & 0.155 & 0.078 & $0.167^{*}$ & 0.162 & $0.174^{*}$ & 0.116 \\
\hline 6) I show consideration to my partner & $0.195^{*}$ & 0.078 & 0.054 & 0.054 & 0.095 & -0.064 & 0.097 \\
\hline 7) I verbally express love to my partner & $0.203^{*}$ & 0.078 & $0.202^{\star}$ & 0.112 & $0.193^{\star}$ & 0.141 & 0.096 \\
\hline 8) My partner verbally expresses love to me & $0.188^{\star}$ & $0.177^{\star}$ & $0.182^{\star}$ & $0.234^{\star *}$ & 0.115 & 0.093 & 0.088 \\
\hline $\begin{array}{l}\text { 9) I understand my partner's wishes and needs } \\
\text { during everyday life }\end{array}$ & $0.303^{\star *}$ & $0.206^{*}$ & 0.122 & $0.197^{\star}$ & 0.132 & 0.050 & 0.098 \\
\hline $\begin{array}{l}\text { 10) I am satisfied with physical contact, such } \\
\text { as hugging or holding hands, during everyday } \\
\text { life }\end{array}$ & $0.315^{\star *}$ & $0.260^{\star *}$ & 0.141 & $0.258^{\star *}$ & $0.242^{\star *}$ & 0.137 & $0.193^{*}$ \\
\hline \multicolumn{8}{|l|}{ Sexual communication } \\
\hline $\begin{array}{l}\text { 11) My partner verbally expresses sexual } \\
\text { satisfaction to me }\end{array}$ & 0.082 & 0.076 & 0.073 & 0.143 & 0.092 & 0.020 & -0.006 \\
\hline $\begin{array}{l}\text { 12) My partner verbally expresses sexual } \\
\text { desire to me }\end{array}$ & 0.060 & 0.107 & 0.134 & $0.193^{*}$ & 0.162 & 0.098 & -0.006 \\
\hline $\begin{array}{l}\text { 13) I verbally express sexual satisfaction to my } \\
\text { partner }\end{array}$ & 0.139 & 0.109 & $0.222^{\star *}$ & $0.279^{\star *}$ & 0.106 & 0.070 & -0.054 \\
\hline $\begin{array}{l}\text { 14) I am satisfied with the content of our } \\
\text { sexual relations }\end{array}$ & 0.137 & 0.125 & $0.223^{* *}$ & $0.231^{\star *}$ & 0.146 & 0.072 & -0.010 \\
\hline $\begin{array}{l}\text { 15) I verbally express sexual desire to my } \\
\text { partner }\end{array}$ & $0.250^{* *}$ & $0.180^{*}$ & $0.211^{\star}$ & $0.199^{\star}$ & 0.134 & 0.087 & $0.190^{*}$ \\
\hline $\begin{array}{l}\text { 16) I am satisfied with the frequency of our } \\
\text { sexual relations }\end{array}$ & 0.122 & 0.090 & $0.216^{* *}$ & $0.186^{\star}$ & $0.172^{\star}$ & 0.140 & -0.029 \\
\hline
\end{tabular}

Spearman correlation coefficients (rs) are shown. ${ }^{*} p<0.05,{ }^{* *} p<0.01$. SFE_10: Family's interactions with non-cohabitating relatives, SFE_11: Family's receiving emotional support from non-cohabitating relatives, SFE_12: Family members' interactions with their friends, SFE_13: Family members' receiving emotional support from friends, SFE_14: Family's interactions with neighbors, SFE_15: Family's participating in community activities (block association, etc.), SFE_16: Family's being comfortable living in the neighborhood.

and "Family members' cooperation in providing care during illness and convalescence." It is a fact that some IBD patients have difficulty in continuing their jobs, as is clear from data that half of IBD patients have the experience of quitting their job or changing jobs [4] [11]. The employment situation that is directly affected by the repetition of remission and recurrence of IBD may not be resolved by means of mutual interaction between spouses. Moreover it is surmised that family functioning per se lacks the spare energy to engage in care of a family member. 
As correlation was observed between "Bonds of affection between family members" and "Family members" being comfortable at home" with all items of "Physical contact," the partners' daily interaction strengthened ties between family members, and by making possible tranquility within the family could be said to be related to enhancing bonds of affection between family members and family's emotional functioning, indicating the importance of daily interaction. One outstanding aspect is the high correlation between "I think that my partner shows consideration to me" and "My partner tries to understand my wishes and needs during everyday life" and family functioning. By showing empathy and love to one's partner, and receiving the partner's empathy in return, the wishes and needs of the IBD patient are understood, and it is believed that awareness being treated by an affirmative attitude by one's partner leads to greater feelings of love and contentment, thereby enabling psychological stability. Consequently it is crucial for medical professionals to provide support so that IBD patients are aware they are being treated with an affirmative attitude by their partner.

Moreover in this study, correlation was observed between satisfaction with physical contact and family functioning. In the domain of "Sexual communication," verbal expressions for sexual desire were correlated with more items such as bonds, contentment, being able to discuss one's troubles, and so on. It is a fact that Japanese people, when compared with people in the west, do not engage in physical contact on a daily basis and are also poor at expressing sexual desire verbally. It is believed that physical contact and expressing sexual desire verbally are important in enhancing family functioning. This suggests the need for medical professionals to be able to provide support through encouragement of physical contact and verbal expression of sexual desire.

\subsection{Daily Interaction Including Physical Contact between Spouses and the Child Rearing Environment}

Correlation was observed for all of the items of "Daily interaction" and "Sexual communication" with "Family members' cooperation in child rearing." At times when relations between spouses were not agreeable children's emotions become unstable, and it was clear that unstable emotions between spouses affected children's way of life [12] [13]. Satisfaction with physical contact and engaging in sexual relations, and expressing each other's sexual desire help to stabilize the couple' feelings. Consequently, the couple's closeness is believed to be one condition for adjusting the child rearing environment and facilitates child rearing through cooperation between family members. Together with satisfaction with physical contact, this indicated the highest correlation. For children to view closeness between parents is considered an conducive to an environment for raising emotionally stable children. Improvement of sexuality had the strongest relationship along with cooperation in child rearing. The basis of family relations is the relations between husband and wife, and to conduct cooperative child rearing, it is believed this indicates the first priority should be the strengthening of the husband and wife system. 


\subsection{Relationship with Ease of Obtaining Nearby Support and Maintenance of Family Functioning}

IBD patients suffer from recurrences of such symptoms as diarrhea and abdominal pain, and when these symptoms occur they are unable to fulfill their roles as family members, so in many cases support from outside the family is needed. Consequently when the symptoms appear, it is important to have someone to seek support. IBD patients have expectations toward those who understand the situation with which they are confronted, and seek support that has the ability to get things done [14]. Consequently, support from nearby relatives and friends is essential in maintaining family functioning.

In this study the satisfaction obtained through awareness of empathy by a partner, awareness of desire to understand, and obtaining satisfaction from skin ship correlate with support by relatives and friends. Relatives and friends are linked to the family external environment. There is a high possibility that these relatives and friends who provide support are close to the IBD patient. The partners of IBD patients understand his or her condition, and is likely to demonstrate a receptive attitude toward support by the patients' relatives or friends. It has been reported that when the family functioning of the families of IBD patients is compared with those of patients with other illnesses, cases where the functioning of the former is good [15], and the closeness between married partners tends to be enhanced through struggling to live with the disease [16]. It is necessary for the family to change its family functioning in accordance with needs, and display strength in harnessing the ability to apply changes. Rather it is believed that the chronic condition enhances sexuality, making it easier to obtain support and thereby maintaining family functioning.

\section{Limitation of the Study}

It is not clear how the mechanisms of domains and items of sexuality interrelate with family functioning. It is believed that further study is needed to clarify the effects of sexuality. Moreover, the number of participants fell short of the targeted figure, making it possible that it is not the representative figure for the population.

From the results of this study, it is important to advise IBD patients that the expression of hopes and desires of daily life, or the conveying love verbally and through physical contact, may relate to their family's psychological stability as well as being beneficial to the child-rearing environment. However, at this point we are uncertain which approaches the patient or the patient's family should take. In the future, it will be necessary to consider effective methods to approach this issue.

\section{Conclusion}

The sexuality of IBD patients has been observed to correlate with family functioning not only in the family internal environment system, but also in the fami- 
ly external environment system. The awareness of empathy shown by the partners of IBD patients relates to the family's emotional functioning in which love and serenity are felt. Daily interaction, which includes physical contact between husband and wife, relates to the family's child rearing functioning by which children are reared through cooperation between husband and wife. Relations by which support from nearby relatives or friends can be easily obtained is tied to the maintenance of family functioning. Consequently it is possible that an approach that elevates the degree of satisfaction of IBD patients' sexuality will elevate family functioning and lead to the direction of family well-being.

\section{Acknowledgements}

We would like to thank the patients who participated in this research, as well as the facility staff and research assistants. This work was supported by JSPS KAKENHI Grant Number 26463390.

\section{Conflicts of Interest}

We declare no conflicts of interest regarding the publication of this paper.

\section{References}

[1] Christensen, B. (2014) Inflammatory Bowel Disease and Sexual Dysfunction. Gastroenterology and Hepatology, 10, 53-55.

[2] Mantzouranis, G., Fafliora, E., Glanztounis, G., Christodoulou, D.K. and Katsanos, K.H. (2015) Inflammatory Bowel Disease and Sexual Function in Male and Female Patients: An Update on Evidence in the Past Ten Years. Journal of Crohn's and Colitis, 9, 1160-1168. https://doi.org/10.1093/ecco-jcc/jjv140

[3] Jedel, S., Hood, M.M. and Keshavarzian, A. (2015) Getting Personal: A Review of Sexual Functioning, Body Image, and Their Impact on Quality of Life in Patients with Inflammatory Bowel Disease. Inflammatory Bowel Diseases, 21, 923-938. https://doi.org/10.1097/MIB.0000000000000257

[4] Li, G., Ren, J., Wang, G., Gu, G., Ren, H., Chen, J., et al. (2015) Impact of Crohn's Disease on Marital Quality of Life: A Preliminary Cross-Sectional Study. Journal of Crohn's and Colitis, 9, 873-880. https://doi.org/10.1093/ecco-jcc/jjv121

[5] Rosenblatt, E. and Kane, S. (2015) Sex-specific Issues in Inflammatory Bowel Disease. Gastroenterology and Hepatology, 11, 592-601.

[6] Miki, Y., Hohashi, N. and Maekawa, A. (2013) A Concept Analysis of Sexuality in Japan's Health and Medical Care Domain. Journal of Japan Academy of Nursing Science, 33, 70-79. https://doi.org/10.5630/jans.33.2_70

[7] Knowles, S.R., Gass, C. and Macrae, F. (2013) Illness Perceptions in IBD Influence Psychological Status, Sexual Health and Satisfaction, Body Image and Relational Functioning: A Preliminary Exploration Using Structural Equation Modeling. Journal of Crohn's and Colitis, 7, e344-e350. https://doi.org/10.1016/j.crohns.2013.01.018

[8] Miki, Y., Maekawa, A. and Hohashi, N. (2016) Development, Validity and Reliability of the Sexuality Satisfaction Index in Patients with Inflammatory Bowel Disease (SEXSI-IBD). Journal of Japanese Society of Stoma and Continence Rehabilitation, 32, 7-20.

[9] Hohashi, N. and Honda, J. (2011) Development of the Concentric Sphere Family 
Environment Model and Companion Tools for Culturally Congruent Family Assessment. Journal of Transcultural Nursing, 22, 350-361. https://doi.org/10.1177/1043659611414200

[10] Hohashi, N. and Honda, J. (2012) Development and Testing of the Survey of Family Environment (SFE): A Novel Instrument to Measure Family Functioning and Needs for Family Support. Journal of Nursing Measurement, 20, 212-229. https://doi.org/10.1891/1061-3749.20.3.212

[11] Ito, M., Togari, T., Park, M.J. and Yamazaki, Y. (2008) Difficulties at Work Experienced by Patients with Inflammatory Bowel Disease (IBD) and Factors Relevant to Work Motivation and Depression. Japanese Journal of Health and Human Ecology, 74, 290-310. https://doi.org/10.3861/jshhe.74.290

[12] Chiba, Y., Kabeyama, K., Suga, S. and Kanaoka, M. (2008) Relationships of Child's Perception of Parents' Childrearing Attitudes with Child's Emotional Stability with Family Members and Attitude towards Life: A Survey of University Students. Japanese Journal of Maternal Health, 49, 366-373.

[13] Kazui, M., Muto, T. and Sonoda, N. (1996) The Roles of Marital Quality and Parenting Stress in Mother-preschooler Relationships: A Family Systems Perspective. The Japanese Journal of Developmental Psychology, 7, 31-40.

[14] Kudo, E. (2011) Self-Care Behavior and Social Support in Adolescents with Inflammatory Bowel Disease (IBD). Journal of Japanese Society of Child Health Nursing, 21, 25-32.

[15] Sakanoue, K. and Kobayashi, N. (2008) The Impact of Inflammatory Bowel Disease on Family Functioning and Quality of Life: A Study of IBD Patients' Society in Kyushu. Japanese Journal of Research in Family Nursing, 14, 32-40.

[16] Miki, Y. (2010) Recognizing and Coping with Troubles Married Women with Stoma Face in Everyday Life. Journal of Japan Academy of Nursing Science, 30, 42-51. https://doi.org/10.5630/jans.30.1_42 


\section{Appendix}

\section{SEXSI-IBD questionnaire}

We ask you to think about your relationship with a sexual partner, spouse, or lover during the previous 12 months when answering the following questions. Please circle the number that most accurately reflects your thoughts. A " 0 " indicates not at all; a "4" indicates most of the time. For questions $21-23$, if you have not had a sexual relationship during the previous 12 months, please select "INAP".

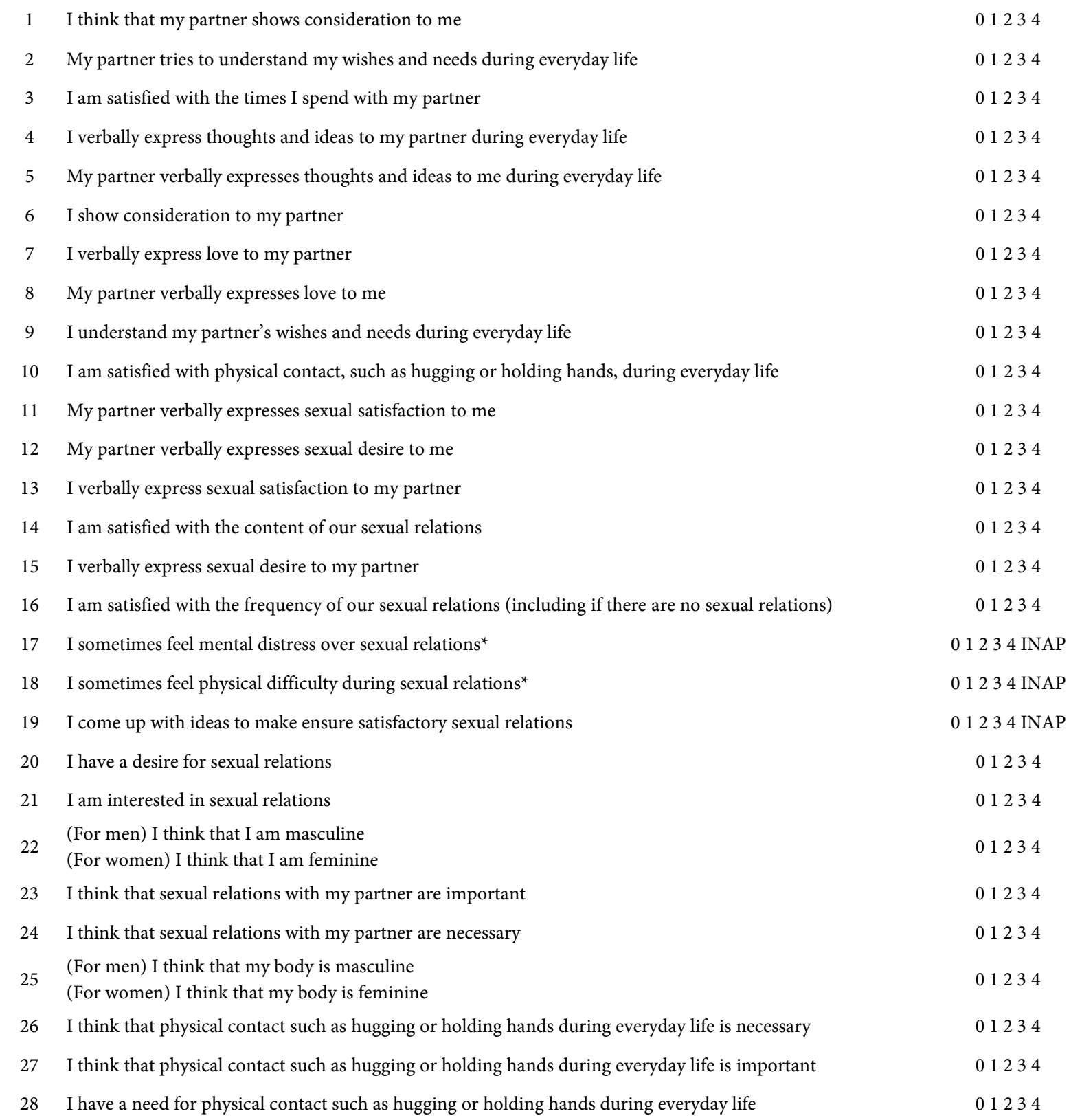

${ }^{\star}$ reverse question items (calculated by inverting the score). 